\title{
Attrition and health in ageing studies: evidence from ELSA and HRS
}

James Banks

University of Manchester, Institute for Fiscal Studies

Alastair Muriel

Institute for Fiscal Studies ali m@ifs.org.uk

James P. Smith

The RAND Corporation

(Received September 2010 Revised February 2011)

\section{Abstract}

This paper investigates the characteristics associated with attrition in the English Longitudinal Study of Ageing (ELSA) and the Health and Retirement Study (HRS), with a particular focus on whether attrition is systematically related to health outcomes and socio-economic status. Our focus is on the attrition of living respondents, not attrition through death, and respondents who died are therefore excluded from our analysis. We have three main results. Firstly, raw attrition is substantially higher in ELSA than in HRS, but whether this is primarily due to differences in the administration of the two surveys, or to other unobserved differences between England and the U.S. is not clear from the available evidence. Second, these differential attrition rates do not change the core conclusions regarding comparisons between the two countries of health and socioeconomic status. Finally, very few observable characteristics predict attrition in either study among respondents in their seventies. Among respondents aged 55-64, wealth appears to predict attrition in the U.S. (but not in England), and low education predicts attrition in England (but not the U.S.). Since the more serious attrition problem exists in ELSA, we conduct additional analysis of attrition in that survey. We find that respondents' level of numeracy strongly predicts attrition, but this does not account for the education gradient in attrition in ELSA.

\section{Introduction}

In recent years, we have witnessed the development of large longitudinal studies of ageing in many countries around the world. The U.S. Health and Retirement Study (HRS), launched in 1992, provided a template for studies such as the English Longitudinal Study of Ageing (ELSA), the Survey of Health, Ageing and Retirement in Europe (SHARE), the Korean Longitudinal Study of Ageing (KLOSA), the Chinese Health and Retirement Survey (CHARLS), the Longitudinal Ageing Survey in India (LASI) and several more surveys in the field or in development in other countries.

These new ageing studies, which share a comparable template, provide rich sources of information for researchers interested in the dynamics of health, socio-economic status, retirement and wellbeing among ageing populations. Their panel nature allows us to investigate the nature and determinants of within person and within household experiences in retirement and health 
onsets, and the manner in which these central life domains co-relate. There are now more than twentyfive countries in the world which have initiated such comparable longitudinal ageing studies and more countries are certainly on the way.

An important concern with all panel studies, and particularly those focused on an older population, is the potential for bias caused by individuals nonrandomly dropping out of the survey over time. If attrition from a survey is systematically related to outcomes of interest or to variables correlated with these outcomes, then not only will the survey cease to be representative of the population of interest, but estimates of the relationships between different key outcomes, especially in a longitudinal context, may also be biased.

The issue of non-response in longitudinal surveys both initial non-response and subsequent attrition has a distinguished history in survey research and statistics (Sudman and Bradburn 1974; Groves and Couper 1998; Little and Rubin 1987). Most of the existing literature has focused on non-ageing panels in the United States, especially during earlier time periods when attrition rates typically were considerably lower. (Becketti et al 1988; Fitzgerald et al 1998; Lillard and Panis 1998; Zapel 1998).

In this paper we present results of an investigation into observable characteristics associated with attrition in ELSA and the HRS, with a particular focus on whether attrition is systematically related to health outcomes and socio-economic status (SES). Investigating the links between health and SES is one of the primary goals of the ELSA and HRS, so attrition correlated with these outcomes is a critical concern.

We begin by looking at raw rates of attrition in the two surveys, and show that panel attrition is a far greater problem in ELSA than in HRS. We consider several possible explanations for ELSA's poorer retention rates, including the greater 'maturity' of HRS (which has been running for ten years longer than ELSA), differences in sampling rules and procedures used in the two surveys, the 'quality' of the two respective survey organizations, and differences in financial incentives offered to respondents. However, the available evidence does not allow us to state definitively whether these explanations, taken together, can account for the disparity in attrition rates between the two surveys.

Having documented raw attrition rates in ELSA and HRS, we then consider the possible bias such attrition could introduce into estimates of disease prevalence derived from the two surveys. In recent papers, we have used data from these surveys to demonstrate that middle aged and older Americans are substantially less healthy than their English counterparts, across a range of important illnesses (Banks et al 2006; Banks, Muriel and Smith 2010). In the same research, we highlighted a substantial socioeconomic gradient in health in both countries, a gradient which is present whether education, income or financial wealth is used as a measure of SES. This gradient persists (in both countries) even after controlling for behavioral risk factors. However, if attrition is systematically related to health and/or SES in ELSA or HRS, this attrition may have implications for our estimates of disease prevalence or for the SES gradient in health. Our earlier research focused on two age groups in England and the United States those aged 55 to 64 , and an older group aged 70 to 80 , since focusing on reasonably tight age groups helps to ensure that observed health and socioeconomic gradients are not driven purely by variation in health or socio-economic status by age. Since one of the aims of this paper is to ascertain the robustness of our earlier results to patterns of attrition, it is those same age groups on which we focus in this paper.

Having established that attrition does not change the core conclusion of this previous work - that Americans have higher rates of disease prevalence at older ages than the English - we go on to a broader investigation of observable characteristics which systematically predict attrition in the two surveys. We find few observable characteristics that predict attrition in either study among those in their seventies. In the group aged 55-64, wealth appears to predict attrition in the U.S. (but not in England), and low education predicts attrition in England (but not the U.S.). Since the more serious attrition problem exists in ELSA, we conduct additional analysis of attrition in that survey. We find that respondents' level of numeracy strongly predicts attrition, but does not account for the education gradient in attrition in ELSA. 
Many modern longitudinal surveys have adopted the practice of attempting to convince attritors from prior waves to return as participants in the panel. This retrieval of prior wave attritors may be important in maintaining the long run viability of the panel. Given the rising importance of returnees in panel studies, we present a 'returnee' analysis for both the HRS and ELSA surveys.

This paper is divided into six sections. Section 1 summarizes the data used in our analysis, while the following section describes the most salient patterns of attrition in HRS and ELSA. The third section evaluates some possible reasons for the much higher rate of attrition in ELSA compared to HRS. Section 4 sets out comparative patterns of disease prevalence in the two countries, and explores how these patterns might be altered when we take into account attrition. Section 5 presents models that attempt to identify personal attributes that appear to predict subsequent attrition in both countries. The final section contains our main conclusions.

\section{Data}

This research presents evidence from two comparably designed ageing studies in the U.S. and England respectively. The studies were purposely designed to be very comparable in terms of population sampling, periodicity, broad content, and in many cases even the specific wording of questions. The Health and Retirement Study (HRS) is a nationally representative sample of the population aged 50 and over in the United States (Juster and Suzman 1995). The initial HRS cohorts were sampled in the early 1990s and subsequent cohorts have been added to establish and maintain full age representation of the post age fifty population. Follow-ups have taken place at two-year intervals since 1992. In this research we use a sample of non-Hispanic Whites in both countries, to ensure greater comparability between the U.S. and English samples. For example, it is well known that African-Americans suffer much worse health outcomes in the U.S. (Hayward et al 2000) and we want our cross-country comparisons to be independent of the quite distinct racial and ethnic composition of the countries.

Questions were asked in each HRS wave about self-reports of general health status, the prevalence and incidence of many chronic conditions, functional status and disability, and medical expenditures. Other related health variables include depression scales, health insurance, smoking and physical exercise.

Data from England come from the English Longitudinal Study of Ageing (ELSA). In ELSA, around 12,000 respondents from three separate years of the Health Survey for England (HSE) survey (those who responded in the years 1998, 1999 and 2001) were recruited to provide a representative sample of the English population aged 50 and over. Detailed employment, income, wage, and asset modules have been fielded and the quality of the baseline data appears to be quite high. The first wave of ELSA was conducted in 2002 and three waves are available for this research.

ELSA content is especially rich in the health domain. Its health module collects information on self-reported general health, specific diagnoses of disease (hypertension, heart disease, diabetes, stroke, chronic lung diseases, asthma, arthritis and osteoporosis, cancer, and emotional and mental illness including depression, memory and cognitive assessment, disability and functioning status (e.g. ADLs and IADLs), health behaviors (smoking, alcohol consumption, and physical activity), and symptoms of heart disease (dizziness and chest pain). While not identical, many of these modules closely parallel those available in HRS. For prior lifetime prevalence, both surveys collect data on individual self-reports of specific diseases of the general form 'Did a doctor ever tell you that you had ...'.

Both HRS and ELSA are known to have directly comparable high quality measurement of several dimensions of socio-economic status - importantly, for our purposes, education and income - as well as demographic variables. A unique aspect of both these surveys is that they also contain high-quality wealth modules using a comprehensive and detailed set of questions on the important components of wealth (Juster and Smith 1997).

Finally, both surveys also track the mortality of survey participants, even among those who left the survey in the years before their death. Each survey is matched to the relevant country's National Death Index (which includes information about date and cause of death of all respondents regardless of their 
participation in subsequent waves of the survey). ${ }^{1}$ These matches with the national death indexes are highly successful - over $95 \%$ of individuals give permission for their records to be linked and are successfully matched.

This mortality information is important for our analysis, since it allows us to distinguish between those who dropped out of each survey voluntarily (despite still being alive) from those who simply died. In this paper we define individuals as having 'attrited' if they do not respond to the survey, but are not dead according to the mortality data.

For the purpose of maintaining comparability, in this paper we use the 2002, 2004 and 2006 waves from ELSA as well as from the HRS, since these are the only years for which ELSA data is currently available. We will discuss below the implications of this choice for the conclusions that we derive from the HRS.

\section{Patterns of Attrition in ELSA and the HRS}

Losses from the sample in panel surveys of the elderly can be traced to two main sources - mortality and sample attrition. Sample attrition is more complicated given that both HRS and ELSA have, as part of their design, an attempt to bring back into the panel respondents who previously attrited. Another complication in comparing these surveys is that by the time of the beginning of the ELSA panel, HRS was a more mature panel in that some respondents had been interviewed for as many as six waves. In this section, we highlight the most salient patterns of sample lost in HRS and ELSA over the same period of time - calendar years 2002 to 2006 - the maximum window allowed in ELSA.

Figure 1 compares rates of attrition and mortality among 55-64 year olds in ELSA and the HRS, between 2002 and 2006 (these years comprise the first and third waves of ELSA). For HRS respondents, the years 2002 and 2006 correspond to different wave numbers depending on which cohort they belonged to, extending from the sixth and eighth wave for the original HRS cohort (51-61 years old in 1992) who would have largely aged out of the 55-64 year old age group in 2002, to the third to fifth wave for those cohorts added to the HRS in 1998. (Further details regarding the HRS's cohort design are given in Section 3 , below.) 
Figure 1. Retention, attrition and death in ELSA and the HRS, 2002-2006

55-64 year olds, by health condition at baseline (2002)

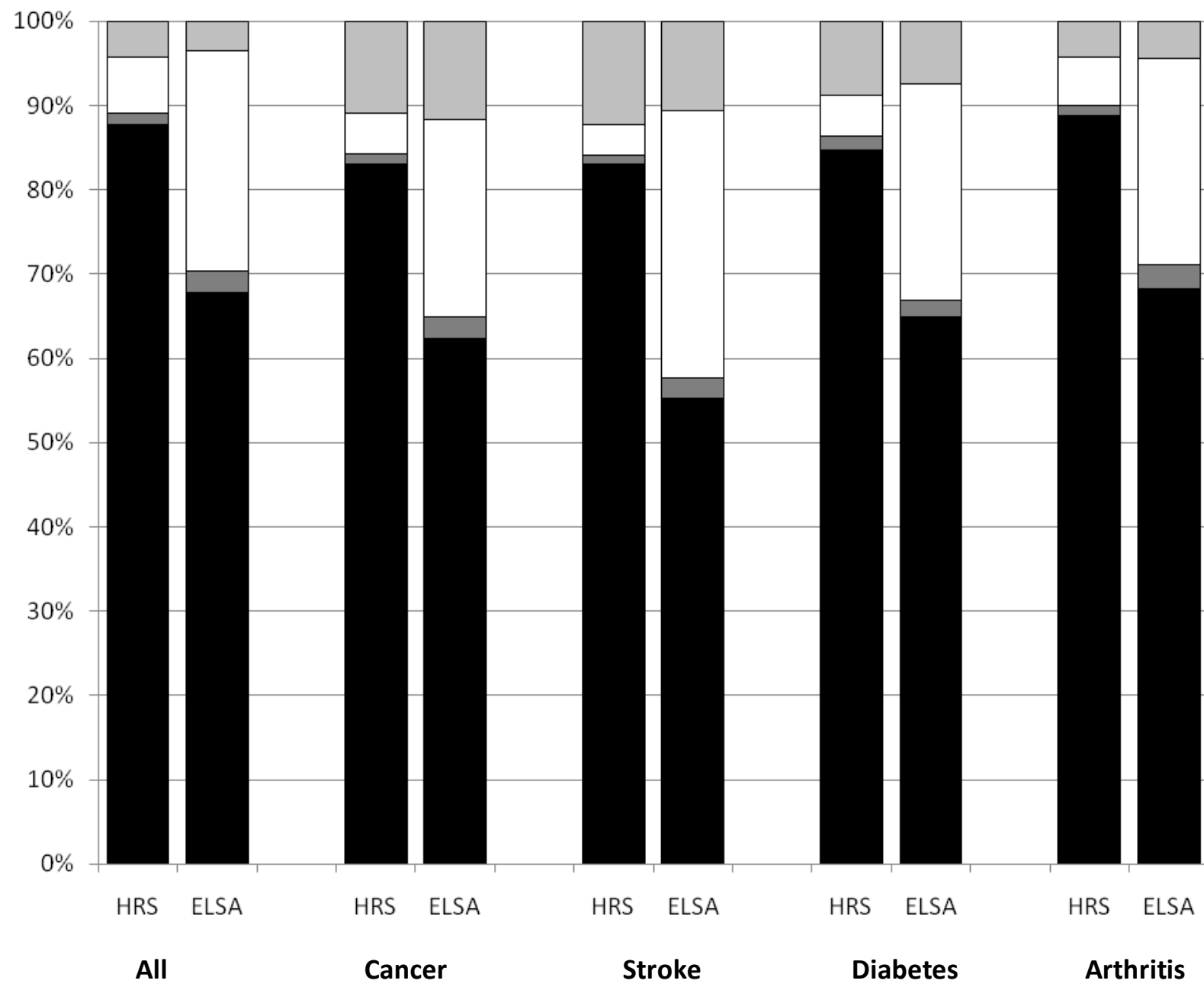

$\square$ Died 2002-2006

$\square$ Attrited 2002-2006

$\square$ Returned (In 2002 attrited 2004,

returned 2006)

- In all three waves

(2002, 2004 and

2006) 
We divide individuals who responded in 2002 into four mutually exclusive categories: (1) those who responded to all three survey waves (2002, 2004 and 2006); (2) those who responded in 2002 but did not respond in 2006 (having dropped out of the survey either in 2004 or in 2006). We refer to these individuals as 'attriters'; (3) those who responded in 2002, did not respond in 2004, but returned to the survey in 2006. We refer to these individuals as 'returners'; (4) those who responded in 2002, but subsequently died. It should be noted that the category whom we label 'attriters' may become 'returners' in future waves if they come back into the survey. Our categories only apply for events that occurred within the survey window 2002-2006.

Looking at the two leftmost bars in Figure 1, which show attrition rates for the 55-64 year old sample in both HRS and ELSA, it is immediately apparent that attrition is substantially higher in ELSA. $88 \%$ of HRS respondents in this age group responded to all three waves, while in ELSA this fraction is just $68 \%$. Moreover, this large difference in retention is not accounted for by differential mortality in the two countries, which shows broadly similar overall mortality rates in both countries (around $4 \%$ in this age group). It is differential attrition which accounts for the disparity - with ELSA having an attrition rate across two waves nearly four times higher than the rate in HRS (less than 7\% of HRS respondents drop out of the survey between 2002 and 2006, compared with more than $26 \%$ in ELSA). Our final category, the 'returners' who drop out in 2004 but return in 2006, comprise $2.6 \%$ of the ELSA sample, and $1.3 \%$ of the HRS sample. As a fraction of those who did attrit between 2002 and 2004, HRS was also more successful in 'recovering' individuals who drop out of the survey. $15 \%$ of HRS attriters subsequently return, compared with less than $10 \%$ of attriters in ELSA.

The remaining bars in Figure 1 illustrate how rates of retention, attrition and mortality vary according to disease prevalence in 2002, among four diseases for which we have comparable information in the HRS and ELSA - cancer, stroke, diabetes and arthritis. Not surprisingly, among individuals who had been diagnosed with cancer at baseline, retention rates are lower than for the full sample $(83 \%$ in the HRS, $62 \%$ in ELSA), and the same holds true for individuals diagnosed with stroke ( $83 \%$ retention in the HRS, 55\% in ELSA). However, much of this lower retention stems from mortality, rather than attrition, with mortality rates of $10-12 \%$ in both countries among respondents diagnosed with stroke or cancer. Rates of attrition among cancer sufferers are actually lower than those for the full sample in both countries $15 \%$ in the HRS, $23 \%$ in ELSA). Among individuals diagnosed with stroke, attrition rates are lower than the rate for the full sample in the HRS (4\% of stroke victims attrited), but higher in ELSA (32\% attrition among stroke victims). For the two less severe conditions, diabetes and arthritis, retention rates are broadly unchanged from those observed in the full sample (around two thirds retention in ELSA, and four fifths in the HRS).

Figure 2 provides the same breakdown of retention, attrition and mortality for our older age group - individuals aged 70 to 80 . Retention rates are once again higher in the HRS, which retained over $78 \%$ of 70-80 year olds between 2002 and 2006, compared with less than $63 \%$ in ELSA. Again mortality rates are broadly similar in both countries (around $15 \%)$, with the difference in retention driven entirely by ELSA's higher attrition - nearly $23 \%$, compared with just $6 \%$ in the HRS. 
Figure 2. Retention, attrition and death in ELSA and the HRS, 2002-2006 70-80 year olds, by health condition at baseline (2002)

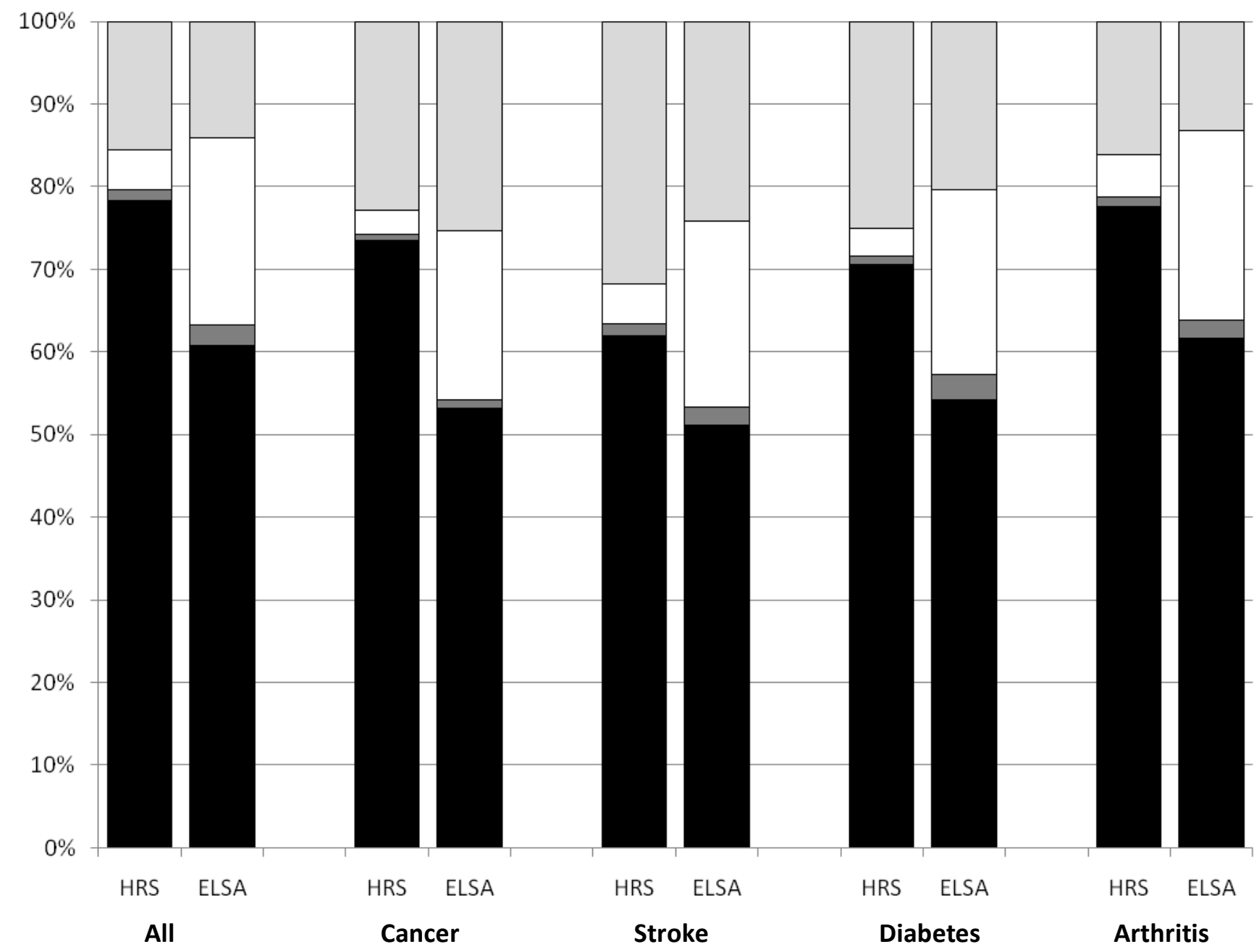

$\square$ Attrited 2002-

2006

$\square$ Returned (In 2002, attrited 2004

returned 2006)

In all three waves (2002, 2004 and

2006) 
Turning to rates arrayed by baseline disease prevalence, we again find lower retention rates among individuals who had been diagnosed with cancer at baseline - $74 \%$ of cancer sufferers are retained in the HRS, and $53 \%$ in ELSA. For stroke victims, retention rates are lower still in both surveys $-62 \%$ in the HRS, $51 \%$ in ELSA. As with the younger age group, these differences in retention are driven by mortality rather than attrition. The mortality rate among cancer sufferers is $23 \%$ in the HRS, $25 \%$ in ELSA. Among those diagnosed with stroke, the mortality rate is $32 \%$ in the HRS, $24 \%$ in ELSA. Similarly, diabetes is not associated with significantly higher attrition in this age group, but is associated with higher mortality - $25 \%$ of diabetes sufferers in the HRS had died by 2006 , as had $20 \%$ of those in ELSA. Arthritis, however, is not associated with either higher attrition or mortality.

In summary, we have demonstrated that attrition is a far greater problem in ELSA than in the HRS, with attrition rates nearly four times higher in the English study. This is true in both the 55-64 and $70-80$ year old age groups. When we examine how rates of attrition vary by baseline disease prevalence, we find similar patterns in both countries, with significantly lower retention among cancer and stroke victims. However, this difference appears to be driven largely by mortality, rather than different rates of attrition.

It is important to point out that the attrition rates in ELSA are not high by the standard of other ageing panels in Europe. For example, in the SHARE survey of twelve continental European countries, the combined lost to sample from attrition and mortality between the first and second waves alone was forty percent. ${ }^{2}$ Since mortality rates are if anything lower in continental Europe, this higher sample lost is due to even greater rates of attrition in SHARE.

Our primary interest in this paper concerns the effects of differential attrition and not lost to sample due to mortality, which has been investigated elsewhere (Attanasio and Hoynes 2000; Banks, Muriel, and Smith 2010). With that objective in mind, in Table 1 we repeat the division of individuals in these age groups into those who remain in all three waves, those who attrit, and those who return - but we now remove individuals who died between 2002 and 2006 from the sample. Table 1 also adds an extra category: 'healthy' individuals, who are not suffering from any of the conditions listed in the table, and are also free from heart conditions ${ }^{3}$. Removing deaths from the sample in this way makes clear that, among the 55-64 year old age group, attrition appears to be slightly lower among individuals who are suffering from health problems at baseline (with the exception of stroke victims in ELSA, whose attrition rate is $36 \%$ compared with $27 \%$ for the healthy sample). In the 70-80 year old age group, there is no clear association between baseline health and attrition. In general, attrition among individuals with baseline health problems is of similar magnitude to attrition among the healthy sample. 
Table 1. Attrition in HRS and ELSA (2002-2006), by pre-existing health condition (excluding deaths)

$\begin{array}{llll}\text { In all three } & \text { Attrited } & \text { In 2002, } \\ (2002,2004 & \text { 2002-2006 } & \begin{array}{l}\text { attrited 2004, } \\ \text { returned 2006 }\end{array} \\ \text { and 2006) } & & \\ \text { waves } & & \end{array}$

55 to 64 year olds

(\%) :

All

$\begin{array}{lllll}\text { HRS } & 91.7 & 7.0 & 1.4 & 4,368\end{array}$

Healthy*

ELSA

70.3

27.0

2.7

3,482

HRS

90.1

8.6

1,3

1,719

ELSA

70.8

26.6

2.7

1,502

Cancer

HRS

93.2

5.4

1.5

411

ELSA

70.7

26.4

2.9

173

Stroke

HRS

94.6

4.2

1.2

165

ELSA

61.8

35.5

2.6

76

Diabetes

HRS

92.9

5.2

1.9

547

ELSA

70.2

27.8

2.0

196

Arthritis

HRS

92.8

6.0

1.3

2,221

ELSA

71.3

25.5

3.1

988

70 to 80 year olds

(\%) :

All

HRS

92.9

5.6

1.5

3,482

ELSA

70.7

26.5

2.8

2,210

Healthy*

HRS

92.9

5.6

1.6

827

ELSA

71.7

24.8

3.5

537

Cancer

HRS

95.3

3.9

0.9

571

ELSA

71.3

27.3

1.3

150

HRS

90.8

7.0

2.2

272

Stroke

ELSA

67.4

29.7

2.9

137

HRS

94.2

4.6

1.3

550

Diabetes

68.1

28.2

3.7

216

Arthritis

HRS

92.6

6.0

1.5

2,278

ELSA

71.0

26.4

2.6

889

\footnotetext{
* Note. 'Healthy' individuals are those free from all conditions listed in this table and free from heart problems. As explained in endnote 2, heart problems are not included directly in Table 1, as we do not have a perfectly comparable measure of heart complaints between the two surveys.
} 


\section{Explaining the higher attrition rate in ELSA}

Why is the attrition rate in ELSA so much higher than in HRS? Numerous factors contribute to a panel survey's retention rate, so it is worth considering potential explanations for ELSA's high rate of attrition compared with HRS. One obvious place to start is the differing 'maturity' of the two panels in 2002. More mature panels may be characterized by lower rates of attrition since the least committed respondents may have long since gone.

Gauging the relative 'maturity' of the ELSA and HRS panels is not entirely straightforward. On the HRS side, in 2002 some respondents (the original birth cohort ages 51-61 in 1992 who would be 61-71 years old in 2002) were in their sixth wave of participation. The AHEAD cohort was initially sampled in 1995 when they were seventy years old or over, so that the 2002 wave was their fifth wave. In 1998, two new cohorts were added - the Children of the Depression Age (CODA-62-69 years old in 1992) and the War Babies cohort (born between 1942 and 1947 and between ages 55-62 in 2002). These two new cohorts were in their third wave of participation in 2002. In summary, HRS respondents in 2002 had previously participated in the survey from anywhere between three to six waves. It is possible, therefore, that individuals with a high propensity to drop out had already left the HRS by $2002 .{ }^{4}$

Measuring the 'maturity' of the ELSA sample is not entirely straightforward either. As explained above, all ELSA respondents were recruited from three prior waves of the Health Survey for England (HSE) so that 2002 actually represented their second wave of participation in a survey with varying years of periodicity depending on the year of their HSE interview (1998, 1999 or 2001). Since the first ELSA wave ultimately achieved a household response rate of $70 \%$ of age-eligible households (Marmot et al 2003), the residual $30 \%$ non-response might also be considered a form of attrition. However, treating individuals' initial HSE interview as their 'first' wave would also be a misleading basis for comparison with the HRS, since HSE respondents were agreeing to a single interview (the HSE is not a longitudinal survey), while HRS respondents were explicitly signing up to take part in a longitudinal survey. For this reason, we use the first (2002) ELSA wave as our basis comparison, since 2002 is the first year that both English and American respondents were agreeing to take part in longitudinal surveys.

The problem remains, however, that HRS respondents had (on average) been members of the panel for more waves than ELSA respondents by 2002, having initially joined the survey in an earlier calendar year. We can look for evidence of the effect this has on attrition by examining retention rates among new HRS cohorts, who were being interviewed for the first time. While there was no new HRS cohort in 2002, there was a new cohort of 51 to 56 year olds added to the HRS in 2004. One problem with using this new cohort is their relatively young age, since younger working respondents tend to exhibit higher attrition. The attrition rate for this cohort between 2004 and 2006 was just $10.6 \%$. A new cohort was also added to the HRS in 1998 - and attrition rates for this cohort were lower still: just $7.3 \%$ to the next wave in 2000, perhaps indicating that attrition rates in surveys in western countries have risen over time. Among ELSA respondents aged 51 to 56, between their first and second waves (2002 to 2004), attrition was $19 \%$. The 'mature survey' explanation, therefore, cannot by itself explain much of the disparity in attrition rates.

Another possible explanation would centre on different levels of mobility in the two countries. A key challenge for any household panel study is simply keeping track of families as they move over time. But mobility at older ages is actually much higher in the United States than it is in England (Banks, Oldfield and Smith 2009), which would argue for higher attrition in the U.S. than in England. This, clearly, cannot explain the higher rates of attrition in ELSA.

Differential 'respondent burden' is another oftcited reason for non-response (Groves and Couper 1998; Zabel 1998). Given how closely ELSA's questionnaire was modeled on the HRS, this explanation is unlikely - average interview length is almost identical (around one and a half hours) in both surveys, and many of ELSA's questions and modules are directly based on HRS counterparts. Nonetheless, it remains possible that respondents in the two countries simply react differently to (objectively 
reasonably similar) questionnaires, so we cannot rule out the issue of respondent burden entirely.

A more significant difference between the two surveys, however, is found in the financial incentives (or 'rewards') that are offered to respondents to thank them for taking part. Both ELSA and the HRS offer such rewards, but the HRS offers a considerably larger sum: $\$ 100$ per person, compared to $£ 10$ per person (around $\$ 15$ at current exchange rates) in ELSA, for the waves that we are considering here. Both theoretical considerations (e.g. Hill and Willis 2001) and experimental evidence (Rodgers 2002) suggest that larger financial incentives may drive improved retention, though as Laurie and Lynn (2009) note, much of our experimental evidence regarding the effectiveness of financial incentives derives from cross-sectional, rather than longitudinal, surveys. Nonetheless, it is certainly possible that ELSA respondents may be under-incentivized compared to HRS respondents, contributing to the different levels of attrition seen in the two surveys.

ELSA and HRS also differ somewhat in their sampling methodology in the treatment of individuals and households. ELSA is a sample of households, so that if a household is randomly chosen for interview, all age-eligible individuals in that household (everyone aged 50 and over) will be added to the ELSA sample. HRS, in contrast, is a sample of families, so that when an individual aged over 50 is selected for interview, their partner (if they are part of a couple) will also be sampled for the HRS. But other members of the household will not be added to the HRS sample, regardless of whether or not their age would make them eligible.

Table 2 addresses this issue directly, by investigating attrition rates at the household level (for all respondents in the survey, regardless of their age) between 2002 and 2004, according to the number of respondents in the household. In this Table, we exclude all households in which a death occurred. We divide households into three categories: (1) households which do not attrit at all (no household members leave the survey): (2) households which partially attrit (some but not all household members leave the survey) and (3) households which completely attrit (all members of the household leave at the same time).

Table 2. Attrition at the Household Level

\section{Number of respondents in household}

\begin{tabular}{|c|c|c|c|c|c|c|c|c|}
\hline & \multicolumn{2}{|c|}{1} & \multicolumn{2}{|c|}{2} & \multicolumn{2}{|c|}{3} & \multicolumn{2}{|c|}{ All } \\
\hline & ELSA & HRS & ELSA & HRS & ELSA & HRS & ELSA & HRS \\
\hline $\begin{array}{l}\text { No household } \\
\text { members attrit }\end{array}$ & $75.2 \%$ & $92.7 \%$ & $73.0 \%$ & $95.1 \%$ & $43.3 \%$ & NA & $74.0 \%$ & $94.9 \%$ \\
\hline $\begin{array}{l}\text { Some household } \\
\text { members attrit }\end{array}$ & $0.0 \%$ & $0.0 \%$ & $8.0 \%$ & $1.4 \%$ & $46.7 \%$ & NA & $4.2 \%$ & $0.7 \%$ \\
\hline $\begin{array}{l}\text { All household } \\
\text { members attrit }\end{array}$ & $24.8 \%$ & $5.3 \%$ & $19.0 \%$ & $3.5 \%$ & $10.0 \%$ & NA & $21.8 \%$ & $4.4 \%$ \\
\hline Total & $100 \%$ & $100 \%$ & $100 \%$ & $100 \%$ & $100 \%$ & NA & $100 \%$ & $100 \%$ \\
\hline $\begin{array}{l}\text { Number of } \\
\text { households }\end{array}$ & 3,802 & 5,850 & 3,921 & 5,352 & 30 & 0 & 7,761 & 11,202 \\
\hline
\end{tabular}

Note. Deaths have been excluded from the sample, so do not count as attrition. 
Overall the attrition of at least one household member is quite high in ELSA when there are three or more respondents in the household, though such households are also less likely than one- or tworespondent households to see all household members attrit. Since this situation involves only thirty households in ELSA, however, it cannot account for differential attrition between the surveys.

The more relevant case is when there are two respondents in the household - typically the wife and husband. Sampling partners was an innovation of both HRS and ELSA and stands in sharp contrast to typical panels such as the Panel Study of Income Dynamics, which rely on a single respondent who answers questions for both partners (Fitzgerald et al 1998). Existing research has shown that the quality of health information reported for the partner is much lower (Weir and Smith 2007; Smith 2007). Is this gain in data quality about the partner offset by greater difficulty in keeping people in the sample when there are two of them?

The data in Table 2 suggest there is no additional attrition loss by making both partners panel members. In both HRS and ELSA, overall attrition in two person households is almost identical to that in one person households. Attrition decisions are certainly correlated between spouses, since if one person attrits the probability that the other partner also attrits is about $70 \%$ in both ELSA and HRS. This often occurs when one spouse may deny access to the other in the interviewing process. However, different sampling procedures of households and families in ELSA and HRS design, fail to explain any of the differential attrition between the two surveys.

In addition to this difference in sampling, the two surveys also differ in their default mode of interview. All ELSA interviews are conducted face to face, but HRS interviews can take place either by phone or face to face, with the majority taking place by phone for the non-baseline waves. We might speculate that this could reduce attrition in several ways - whether because some respondents may find it more convenient to answer questions by telephone, or because it may be easier to trace households who have moved when all one needs is a telephone number, rather than an address. While attrition rates in the HRS do not vary by mode of interview, it remains possible that the convenience of a telephone interview may help to reduce attrition overall, since individuals who are willing to accept a phone interview may have refused a face to face interview (and so attrited from the survey).

With the exception of the financial incentives for participation and differing interview modes, few of the other structural differences in survey design that we were able to examine appear likely to account for the substantial difference in attrition between these two surveys. We therefore move on to investigate the extent to which other differences in survey implementation could play a role. After all, one hypothesis that has to be considered is that the HRS survey interview team may be better trained, more experienced or otherwise better equipped to retain sample members compared with the ELSA team. We attempt to cast some light on this question by using information on the retention rates of individual interviewers in ELSA.

For this analysis we use ELSA data linking respondent identifiers to the interviewer who administered their 2002 survey questionnaire. For each interviewer, we can therefore observe the fraction of their 2002 respondents who remained in the survey in 2004. For each ELSA respondent we calculate their interviewer's 'leave one out' retention rate (that is, the interviewer's retention rate for all respondents apart from the individual we are currently considering). This is a number between zero and one, with zero implying that no other respondents questioned by this interviewer remained in the survey (100\% attrition), and one implying that all were retained ( $0 \%$ attrition). We take this as an imperfect but useful indicator of 'interviewer quality'. $^{5}$

Figure 3 shows a histogram of interviewer retention rates (at the interviewer level) between 2002 and 2004. We see that although the distribution is reasonably dense around the mean retention rate of $75.8 \%$, the distribution is quite wide. ${ }^{6}$ The bottom $10 \%$ of interviewers see less than two thirds of their respondents retained in the survey, while the top $10 \%$ see retention of close to $90 \%$ and above. 
Figure 3. Interviewer effects in ELSA (retention rates)

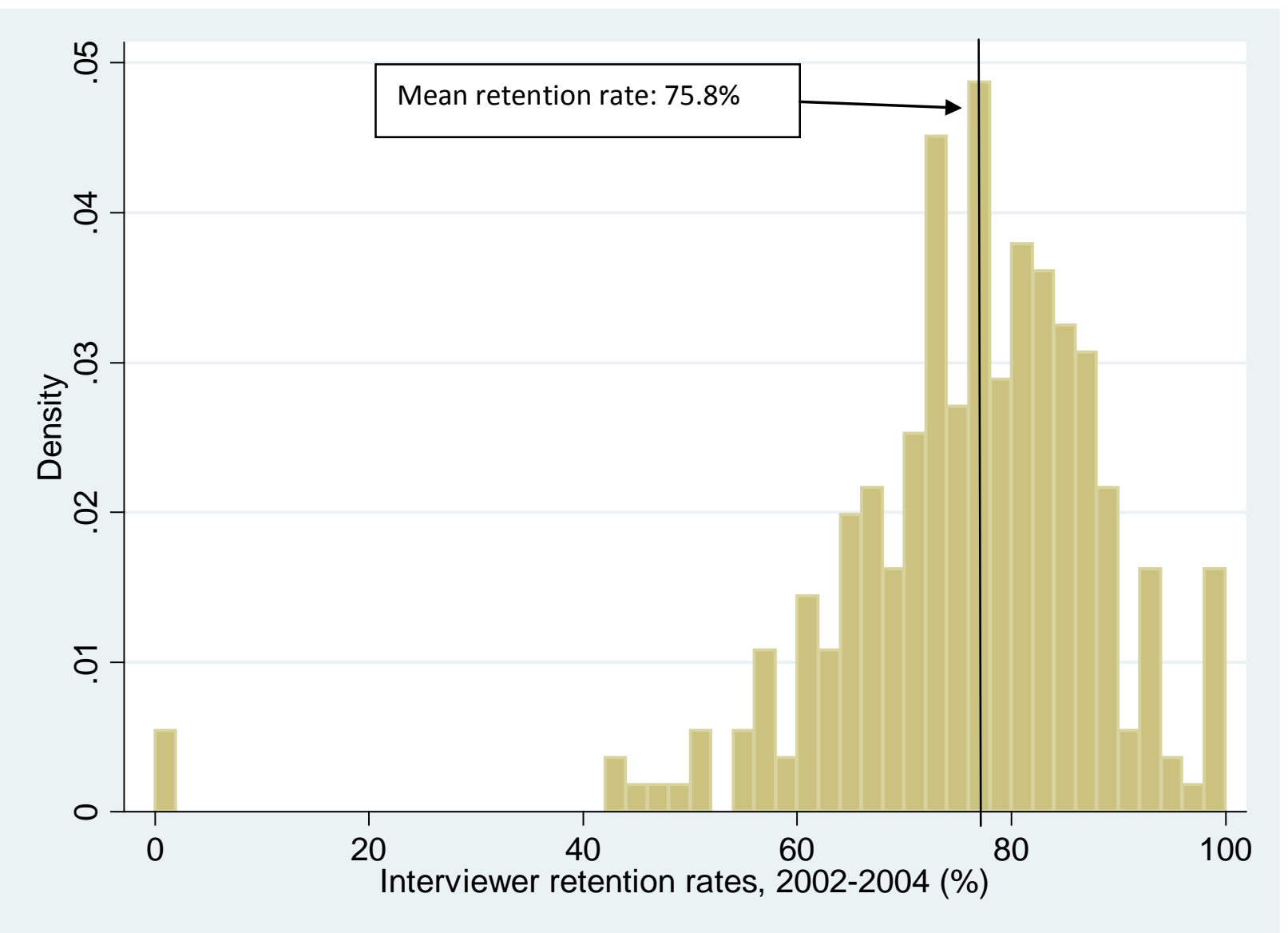

One way of gauging whether the 'quality' of interviewers could account for differential attrition is to eliminate the bottom tail of the ELSA interviewer distribution, and calculate the impact this would have on ELSA's retention rate. As a first calculation, we compute the ELSA retention rate if the bottom $25 \%$ of interviewers had the same mean retention rate as the top $75 \%$. This would improve ELSA's overall (weighted by number of interviews) retention rate by just three percentage points, from $77.6 \%$ to $80.6 \%$. As a more extreme truncation of the interviewer distribution, we compute the ELSA retention rate if the bottom $50 \%$ of interviewers had the same mean retention as the top 50\%. This would increase ELSA's overall retention by less than seven percentage points, from $77.6 \%$ to $84.3 \%$. In fact, for ELSA to match HRS's retention rate of $95.5 \%$, we would need to remove the bottom ninety percent of the interviewer distribution, and allocate them the same mean retention rate as the top ten percent. This is an extremely large change in the distribution of interviewer retention, suggesting that differential interviewer quality is not the primary reason for the ELSA's higher between wave attrition. This should not be surprising since both survey organizations (NatCen in England and ISR in America) are highly respected in their fields.

In summary, while ELSA's attrition rates are significantly higher than those of the HRS, we do not have sufficient evidence to precisely identify the causes. Mobility, maturity of the survey and respondent burden do not seem promising explanations for the gap. Differing sampling methods, interview modes and especially financial incentives 
seem likely to play a role but the precise magnitude of their effects are difficult establish in the absence of experimental variation. Existing research on respondent financial incentives would seem to suggest, however, that this is too large an attrition gap for financial incentives alone to explain (Groves and Couper 1998; Rodgers 2002).

An alternative possibility is that conducting panel surveys with high initial response rates and low rates of attrition is simply more difficult in England (and by extension Western European countries, in light of the SHARE experience) than in the US. Even in the United States, initial response rates of new HRS cohorts have been declining and attrition rates have been rising somewhat, indicating that the scientific challenges in conducting high quality panel surveys are becoming more daunting. In contrast, these challenges appear to be much less severe in developing countries where attrition rates appear to be considerably lower (Thomas et al 2001).

\section{The impact of attrition on estimates of disease prevalence}

We turn next to the impact attrition has on a key outcome of interest - estimates of disease prevalence in the two countries. One of the primary uses of HRS and ELSA involves conducting longitudinal analysis of health status. A concern for both surveys, but particularly ELSA, is the impact that attrition has on key outcomes of interest, such as health and the SEShealth gradient. In this section, we examine the effect of attrition on estimates of disease prevalence.

In previous work (Banks et al 2006), we compared the prevalence of a number of diseases (stroke, lung disease, cancer, hypertension, diabetes and heart problems) among middle age adults (aged 55-64 years old) in England and in the United States. We found that Americans were much less healthy than their English counterparts. These differences were large along all points of the socio-economic status distribution, and were present in biological measures of health as well as self-reported disease prevalence.

In a recent extension of this work (Banks, Muriel and Smith 2010), we examined disease prevalence for an older age group (70-80 year olds), and explored patterns in new onsets of disease ('incidence') among both 55-64 and 70-80 year olds. Using data from ELSA and HRS, Table 3 summarizes the main results. We find that disease incidence and prevalence are both higher among the Americans in age groups 55-64 and 70-80, indicating that Americans suffer not only from higher past cumulative disease risk (as indicated by their higher disease prevalence), but also experience higher immediate risk of new disease onset or incidence compared to the English. 
Table 3. Disease prevalence and incidence in older adults in the US and England

Prevalence in 2002

(\%)

Stroke Lung Cancer HBP Diabetes Heart

Age 55-64

England

US

2.28

3.52

5.62

5.48

8.22

9.57

33.40

42.65

5.88

12.07

8.21

15.50
Heart Sample

attack size

Age 70-80

England

US

7.1

8.28

7.80

47.67

10.38

20.99

10.01

2,706

8.42

12.26

17.92

59.00

17.23

32.06

NA 4,013

Incidence 20022006 (\%)

Stroke Lung Cancer HBP

Diabetes

Heart

Heart Sample attack size

Age 55-64

England

1.70

2.00

2.99

10.17

3.33

2.61

1.85

2,645

US

2.07

3.08

4.26

10.03

6.00

6.25

3.31

3,965

Age 70-80

England

US
4.68

5.51
2.78

3.89
4.80

5.88
9.83

8.31
4.44

4.66
4.80

3.38

9.28

5.42
1,688

3,214

Notes. NA-not available.

Source: England-English Longitudinal Survey of Ageing (ELSA; United States-Health and Retirement Survey (HRS). See Banks, Muriel, and Smith (2010).

Table 4 examines the extent to which the health status of the baseline sample (respondents in 2002) is altered when we restrict the sample in various ways to take account of sample retention. The top row of each panel ("All 2002 respondents") shows disease prevalence for the full 2002 sample - the same numbers shown in Table 3 . In the rows below, we show baseline disease prevalence among four subsamples: (1) individuals who responded in 2002 and were still alive in 2007; (2) individuals who responded in 2002 and were dead by 2007; (3) individuals who responded in 2002 and attrited from the survey by 2006 (but did not die); and (4) the balanced sample - individuals who responded to all three waves, in 2002, 2004 and 2006.

Among our first subgroup, those who remained alive to 2007, we see not surprisingly somewhat lower baseline disease prevalence in both surveys (this is true of both the 55-64 and $70-80$ age groups).
Among those who died between 2002 and 2007, baseline disease prevalence is substantially higher especially among the most serious conditions (stroke, heart attack, lung disease, cancer) where 2002 prevalence is often more than twice as high as in the whole sample.

Our key concern is the effects of attrition on disease prevalence and incidence. Starting with the 55-64 year old age group in ELSA (the top panel of Table 4), baseline disease prevalence among attriters is almost identical to prevalence in the full sample. For the same age group in the HRS, attriters appear if anything to be slightly healthier than the full sample. Turning to the older age group (the lower panels of Table 4), we again observe very small differences in estimated disease prevalence between the attritor and full sample in either ELSA or HRS.

The final row of each panel of Table 4 displays disease prevalence among the three wave balanced 
panel (individuals who responded to the 2002, 2004 and 2006 surveys). Among 55-64 year olds, in both ELSA and HRS, disease prevalence in the balanced panel remains similar to that in the full baseline sample, but is slightly lower for all conditions, largely due to mortality bias and not attrition. In this age group, even the 'survivor' bias is small, since mortality is not high. Among 70-80 year olds, this bias is slightly larger - with lower disease prevalence among the balanced panel for almost all conditions, with 'survivor' bias accounting for almost all the difference.

Table 4. Disease prevalence in the US and England (2002) - the impact of attrition

\begin{tabular}{|c|c|c|c|c|c|c|c|c|}
\hline Prevalence in 2002 (\%) & Stroke & Lung & Cancer & HBP & Diabetes & Heart & $\begin{array}{r}\text { Heart } \\
\text { attack }\end{array}$ & $\begin{array}{l}\text { Sample } \\
\text { size }\end{array}$ \\
\hline \multicolumn{9}{|l|}{ Age 55-64 - England } \\
\hline All 2002 respondents & 2.28 & 5.62 & 5.48 & 33.40 & 5.88 & 8.21 & 4.05 & 3,775 \\
\hline \multicolumn{9}{|l|}{ Responded 2002 and - } \\
\hline Alive in 2007 & 2.11 & 5.18 & 4.91 & 33.14 & 5.65 & 7.69 & 3.63 & 3,643 \\
\hline Dead in 2007 & 6.67 & 17.78 & 18.52 & 39.26 & 12.59 & 20.74 & 14.07 & 132 \\
\hline Attrited by 2006 & 2.81 & 6.73 & 4.72 & 34.17 & 5.93 & 8.04 & 3.52 & 998 \\
\hline Balanced Panel, all waves & 1.84 & 4.55 & 5.06 & 32.97 & 5.57 & 7.61 & 3.69 & 2,548 \\
\hline \multicolumn{9}{|l|}{ Age 55-64-US } \\
\hline All 2002 respondents & 3.52 & 8.22 & 9.57 & 42.65 & 12.07 & 15.50 & NA & 4,437 \\
\hline \multicolumn{9}{|l|}{ Responded 2002 and - } \\
\hline Alive in 2007 & 3.24 & 7.52 & 8.88 & 41.66 & 11.37 & 14.08 & NA & 4,255 \\
\hline Dead in 2007 & 7.74 & 18.06 & 24.47 & 52.49 & 26.04 & 33.04 & NA & 189 \\
\hline Attrited by 2006 & 0.77 & 6.01 & 6.86 & 38.97 & 8.76 & 11.26 & NA & 290 \\
\hline Balanced Panel, all waves & 3.43 & 7.57 & 8.97 & 41.78 & 11.44 & 14.28 & NA & 3,965 \\
\hline Prevalence in 2002 (\%) & Stroke & Lung & Cancer & HBP & Diabetes & Heart & $\begin{array}{l}\text { Heart } \\
\text { attack }\end{array}$ & $\begin{array}{r}\text { Sample } \\
\text { size }\end{array}$ \\
\hline \multicolumn{9}{|l|}{ Age $70-80-E n g l a n d$} \\
\hline All 2002 respondents & 7.17 & 8.28 & 7.80 & 47.67 & 10.38 & 20.99 & 10.01 & 2,706 \\
\hline \multicolumn{9}{|l|}{ Responded 2002 and - } \\
\hline Alive in 2007 & 6.23 & 6.74 & 6.83 & 47.39 & 9.16 & 19.96 & 9.54 & 2,322 \\
\hline Dead in 2007 & 12.66 & 16.38 & 13.15 & 48.88 & 15.14 & 27.05 & 13.40 & 384 \\
\hline Attrited by 2006 & 7.15 & 6.02 & 6.83 & 46.83 & 9.76 & 22.44 & 11.06 & 634 \\
\hline Balanced Panel, all waves & 5.86 & 7.28 & 7.03 & 48.00 & 9.38 & 18.94 & 8.76 & 1,621 \\
\hline \multicolumn{9}{|l|}{ Age $70-80-$ US } \\
\hline All 2002 respondents & 8.42 & 12.26 & 17.92 & 59.00 & 17.23 & 32.06 & NA & 4,013 \\
\hline \multicolumn{9}{|l|}{ Responded 2002 and - } \\
\hline Alive in 2007 & 6.83 & 9.66 & 16.33 & 57.01 & 15.26 & 28.94 & NA & 3.398 \\
\hline Dead in 2007 & 17.87 & 23.20 & 26.85 & 64.05 & 27.85 & 46.88 & NA & 628 \\
\hline Attrited by 2006 & 8.76 & 6.48 & 10.63 & 62.24 & 14.45 & 37.45 & NA & 184 \\
\hline Balanced Panel, all waves & 6.63 & 9.87 & 16.74 & 56.64 & 15.30 & 28.47 & NA & 3,213 \\
\hline
\end{tabular}


While this analysis reveals that a balanced panel does have somewhat lower disease prevalence than the full sample, this bias is driven by mortality, rather than attrition. In addition, the key result is that, no matter how we restrict the sample, Americans have higher disease prevalence than the English in both age groups. This is true whether we look at the full 2002 sample, only those who remain alive, or at the full three wave balanced panel. The choice of these differential samples does not alter that result.

\section{Predictors of attrition}

While individuals who drop out of ELSA and the HRS appear to differ little from the full non- mortality sample in terms of their health, a relation could appear in multivariate analysis or there could be systematic attrition, based on socio-economic status (SES) and other baseline characteristics, that one may want to relate to these health outcomes. In this section, we examine these issues by estimating full multivariate models of attrition in HRS and ELSA.

Table 5 contains estimated marginal effects from multivariate probit models with associated $\mathrm{z}$ statistics in parenthesis. This model is estimated on a dependent variable ('attrited') which is equal to one if an individual dropped out of the survey between 2002 and 2006, and equal to zero if they remained in the survey (responding to both the 2002 and 2006 waves). To highlight the role of attrition, individuals who died have been removed from the sample. Separate attrition models were estimated for those aged 55-64 and those aged 70-80 in 2002 in each country.

The model includes measures of individuals' socioeconomic status (quintiles of baseline wealth ${ }^{7}$ and baseline household income and education level ${ }^{8}$ ) and a dummy variable for labour market status ( $1=$ working). 2002 baseline health status is measured in several ways - a set of dummy variables for the presence of specific diseases at baseline, and separate indicators that a respondent's self-reported health is excellent or very good, good, fair, with the poor response being the left out group. There are also a set of demographic controls for marital status (married, separated, divorced, and widowed, with never married being the excluded class) and housing tenure ( $1=$ home owner). Finally, the model includes a full set of single year age dummies within each age interval which are interacted with sex. For ease of exposition, these age/gender effects are not displayed in Table 5.

Table 5. Models of Attrition - ELSA and HRS

(Probits, marginal effects with $\mathrm{z}$ statistics in parenthesis below)

$\begin{array}{ccccc} & (1) & (2) & (3) & (4) \\ \text { Sample } & \text { ELSA sample } & \text { HRS sample } & \text { ELSA sample } & \text { HRS sample aged } \\ & \text { aged 55-64 } & \text { aged 55-64 } & \text { aged 70-80 } & 70-80\end{array}$

VARIABLES

Attrited from sample between 2002 and 2006

$\begin{array}{lllll}\text { Income } & & & & \\ \text { Income quintile 1 } & 0.015 & -0.016 & 0.046 & -0.026 \\ \text { Income quintile 2 } & (0.53) & (1.09) & (1.17) & (1.73) \\ & -0.004 & -0.028 & -0.006 & -0.024 \\ \text { Income quintile 3 } & (0.15) & (2.18)^{*} & (0.18) & (1.89) \\ & 0.001 & -0.000 & 0.010 & -0.014 \\ \text { Income quintile 4 } & (0.04) & (0.01) & (0.29) & (1.15) \\ & -0.008 & 0.016 & 0.019 & 0.001 \\ & (0.34) & (1.53) & (0.61) & (0.10)\end{array}$




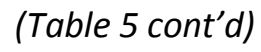

Wealth

Wealth quintile 1

$\begin{array}{lccc}0.055 & -0.016 & 0.071 & 0.020 \\ (1.42) & (1.21) & (1.31) & (0.99) \\ 0.017 & -0.033 & 0.023 & 0.001 \\ (0.61) & (3.03)^{* *} & (0.64) & (0.11) \\ 0.002 & -0.027 & 0.018 & -0.006 \\ (0.06) & (2.68)^{* *} & (0.55) & (0.49) \\ -0.004 & -0.021 & 0.043 & 0.006 \\ (0.17) & (2.25)^{*} & (1.36) & (0.59)\end{array}$

Highest qualification

(ELSA only)

\begin{tabular}{|c|c|c|c|c|}
\hline \multirow[t]{2}{*}{ Degree } & -0.160 & NA & -0.068 & NA \\
\hline & $(6.41)^{* *}$ & NA & (1.63) & NA \\
\hline \multirow[t]{2}{*}{ Below degree } & -0.140 & NA & -0.053 & NA \\
\hline & $(5.85)^{* *}$ & NA & $(1.48)$ & NA \\
\hline \multirow[t]{2}{*}{ A level } & -0.113 & NA & -0.091 & NA \\
\hline & $(3.72)^{* *}$ & NA & $(1.71)$ & NA \\
\hline \multirow[t]{2}{*}{ O level } & -0.065 & NA & -0.030 & NA \\
\hline & $(3.12)^{* *}$ & NA & $(0.94)$ & NA \\
\hline \multirow[t]{2}{*}{ CSE } & 0.034 & NA & -0.078 & NA \\
\hline & $(0.93)$ & NA & $(2.03)^{*}$ & NA \\
\hline \multirow[t]{2}{*}{ Foreign qual. } & -0.080 & NA & -0.044 & NA \\
\hline & $(2.85)^{* *}$ & NA & $(1.36)$ & NA \\
\hline \multicolumn{5}{|c|}{ Vears of education (HRS) } \\
\hline \multirow[t]{2}{*}{ Ed. 13 to 15 (HRS) } & NA & 0.006 & NA & -0.007 \\
\hline & NA & $(0.64)$ & NA & $(0.76)$ \\
\hline \multirow[t]{2}{*}{ Ed. 16+ (HRS) } & NA & -0.013 & NA & -0.002 \\
\hline & NA & $(1.34)$ & NA & $(0.25)$ \\
\hline \multirow[t]{2}{*}{ n work } & 0.031 & 0.004 & 0.015 & -0.000 \\
\hline & (1.69) & $(0.50)$ & $(0.36)$ & $(0.01)$ \\
\hline \multicolumn{5}{|l|}{$\begin{array}{l}\text { Baseline health } \\
\text { conditions }\end{array}$} \\
\hline \multirow[t]{2}{*}{ Angina } & -0.035 & NA & -0.012 & NA \\
\hline & $(1.02)$ & NA & $(0.41)$ & NA \\
\hline \multirow[t]{2}{*}{ Heart attack } & -0.035 & NA & 0.033 & NA \\
\hline & $(0.77)$ & NA & $(0.92)$ & NA \\
\hline \multirow[t]{2}{*}{ Heart failure } & -0.095 & NA & 0.139 & NA \\
\hline & $(0.88)$ & NA & $(1.23)$ & NA \\
\hline \multirow[t]{2}{*}{ Heart prob. (HRS) } & NA & -0.003 & NA & 0.015 \\
\hline & NA & $(0.31)$ & NA & (1.69) \\
\hline
\end{tabular}




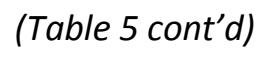

\begin{tabular}{|c|c|c|c|c|}
\hline \multirow[t]{2}{*}{ Stroke } & 0.070 & -0.038 & -0.001 & 0.011 \\
\hline & $(1.26)$ & $(1.94)$ & $(0.02)$ & $(0.74)$ \\
\hline \multirow[t]{2}{*}{ Lung disease } & 0.066 & -0.002 & -0.050 & -0.014 \\
\hline & (1.85) & $(0.18)$ & $(1.36)$ & $(1.16)$ \\
\hline \multirow[t]{2}{*}{ Cancer } & 0.022 & -0.008 & 0.022 & -0.018 \\
\hline & $(0.61)$ & $(0.64)$ & $(0.58)$ & (1.91) \\
\hline \multirow[t]{2}{*}{ High blood press. } & 0.005 & -0.005 & -0.006 & 0.010 \\
\hline & $(0.31)$ & $(0.63)$ & $(0.32)$ & (1.36) \\
\hline \multirow[t]{2}{*}{ Diabetes } & -0.003 & -0.017 & 0.004 & -0.013 \\
\hline & $(0.10)$ & $(1.53)$ & $(0.13)$ & $(1.35)$ \\
\hline \multirow[t]{2}{*}{ Arthritis } & -0.035 & -0.017 & -0.011 & 0.005 \\
\hline & $(1.96)^{*}$ & $(2.29)^{*}$ & $(0.56)$ & $(0.68)$ \\
\hline \multicolumn{5}{|l|}{ Marital status } \\
\hline \multirow[t]{2}{*}{ Married } & 0.022 & -0.047 & 0.020 & -0.005 \\
\hline & $(0.61)$ & (1.91) & $(0.43)$ & $(0.18)$ \\
\hline \multirow[t]{2}{*}{ Separated } & -0.052 & -0.040 & 0.119 & 0.082 \\
\hline & $(0.71)$ & $(1.35)$ & $(0.90)$ & $(0.87)$ \\
\hline \multirow[t]{2}{*}{ Divorced } & -0.018 & -0.132 & -0.114 & 0.007 \\
\hline & $(0.43)$ & $(0.62)$ & $(2.02)^{*}$ & $(0.21)$ \\
\hline \multirow[t]{2}{*}{ Widowed } & -0.057 & -0.005 & -0.065 & 0.014 \\
\hline & $(1.28)$ & (0.19) & $(1.41)$ & $(0.47)$ \\
\hline \multicolumn{5}{|l|}{ Self-reported health } \\
\hline \multirow[t]{2}{*}{ Health ex./v. good } & -0.036 & -0.013 & -0.052 & -0.008 \\
\hline & $(1.00)$ & $(0.66)$ & (1.27) & $(0.48)$ \\
\hline \multirow[t]{2}{*}{ Health good } & -0.057 & 0.000 & 0.027 & -0.003 \\
\hline & (1.63) & $(0.01)$ & $(0.66)$ & (0.19) \\
\hline \multirow[t]{2}{*}{ Health fair } & -0.039 & 0.004 & -0.008 & 0.010 \\
\hline & $(1.12)$ & $(0.17)$ & (0.19) & $(0.57)$ \\
\hline \multirow[t]{2}{*}{ Health: missing } & 0.286 & - & 0.405 & - \\
\hline & $(3.04)^{* *}$ & - & $(3.47)^{* *}$ & - \\
\hline \multirow[t]{2}{*}{ Tenure: owner } & 0.007 & -0.032 & 0.006 & 0.002 \\
\hline & $(0.20)$ & $-(2.19)^{*}$ & $(0.14)$ & $(0.15)$ \\
\hline Observations & 3431 & 4255 & 2189 & 3395 \\
\hline
\end{tabular}

Notes. Robust z statistics in parentheses

* significant at $5 \%$ level, ** significant at $1 \%$ level 
Perhaps the most striking result of these probit models is that even when estimated in a multivariate context, health variables - whether through disease prevalence or self-reported health - in either country and in both age groups, do not predict subsequent attrition from the survey. The only exception to that summary is that respondents suffering from arthritis are less likely to attrit in both countries among those 55-64 years old. Our results from the previous section (finding little evidence of a systematic relationship between health and attrition) are apparently robust to the introduction of a standard set of controls for other attributes ${ }^{9}$.

Turning next to the variables measuring socioeconomic status, we find very different patterns in the two countries. Among 55-64 year olds in ELSA, there is strong evidence that the least educated individuals are more likely to drop out of the survey than their more educated peers. There are no education effects for this age group in HRS. In contrast, the least wealthy respondents in HRS in this age group are the most likely to attrit with no statistically significant income or wealth effects on attrition in ELSA. Among older ELSA and HRS respondents, there appear to be no strong SES correlates of attrition - neither education, income, nor wealth.

In the HRS, there is some evidence that housing tenure predicts attrition among 55-64 year olds, with individuals who own their home slightly less likely to attrit, holding all other attributes constant, possibly reflecting the higher mobility of renters (and consequent increased difficulty in tracing them for future survey waves) compared with owner-occupiers in the U.S. (Banks et al 2009). In ELSA, by contrast, housing tenure does not predict attrition - perhaps reflecting the fact that mobility is low among both renters and owner-occupiers in England (also shown in Banks et al 2009), with a much smaller differential between the two groups than is seen in the U.S.

The strongest predictors of attrition in ELSA actually have nothing to do with personal attributes at all - they are the 'self-reported health missing' dummy variables, indicating that an individual did not answer the self-reported health questions in ELSA's health modul $\mathrm{e}^{10}$. Since refusing to answer questions is likely to indicate that an individual was not wholly committed to the survey, it is perhaps unsurprising that such individuals are less likely to respond to requests for a repeat interview in subsequent waves.

In summary, the only strong indication of SES bias in attrition in ELSA comes from the 55-64 year old age group where it appears that less-educated individuals in this age group are more likely to drop out of the survey. Given ELSA's much higher attrition rate, it is worth investigating the reasons why differential attrition by education might arise.

One possibility is that less-educated respondents simply found the ELSA survey more burdensome to answer than higher-educated respondents did. Having agreed to take part in ELSA's first wave, it is possible that these individuals didn't fully appreciate the demands of the interview and questionnaire. ELSA is a long survey that probes domains of life (and especially the economic domain) that were not addressed in the prior HSE wave. If this was the explanation, we would expect the bulk of attrition of lower-educated respondents to take place between ELSA's first and second waves (2002 to 2004), since such respondents may have had little idea of the survey's contents in 2002 (and so agreed to participate initially), but would have known what to expect from the survey by the second wave in 2004. Between 2004 and 2006, we would therefore anticipate that the education effect would diminish, as all respondents now know what to expect from the survey. This explanation fails our test. We reestimated models in Table 5 separately for attrition from 2002 to 2004, and attrition from 2004 to 2006. For both waves, the coefficients on the education variables are of similar magnitude and statistical significance $^{11}$.

Another possibility is that the education gradient is accounted for by less-educated respondents also having lower levels of numeracy. The ELSA interview involves many questions with numerical answers (notably the income and wealth questions, but also many other sections of the questionnaire), which less numerate respondents may find quantitatively demanding and be less comfortable answering. In our final empirical analysis we examine this possibility directly, as well as investigating the role of other ELSA-specific interview variables on subsequent retention. 
The 2002 ELSA questionnaire asked respondents up to five basic questions involving successively more complex numerical calculations. The six possible questions are presented in Appendix 1 . Answers to all questions are unprompted (i.e. respondents are not given a menu of possible answers to choose from). Each respondent initially receives questions q2, q3 and q4. If all of these are answered incorrectly the respondent receives question $\mathrm{q} 1$ and that is the end of their numeracy module. Otherwise the respondent receives question $\mathrm{q} 5$. If the respondent reports a correct answer to any (or all) of questions q3, q4 and $q 5$, they receive the final and most difficult question q6 that requires an understanding of compound interest.

Using these questions we allocate individuals into one of four groups according to their broad numerical ability. This has the advantage of allowing us to choose groups that have some prevalence in the population, since a simple count of correct answers does not take into account the relative difficulty of the questions and may lead to some clusters where there are many observations, with relatively few individuals at the extremes. The precise coding is indicated in Appendix 1 and has been described and analysed in more detail in Banks and Oldfield (2007).

In Table 6, we repeat the probit model of Table 5 (using the same covariates), but with the addition of a number of variables to capture numeracy, interview outcomes other than the subsequent attrition and possible interviewer effects. Only the marginal effects for education and these additional variables are reported, in order to ascertain whether the education effect is diminished when these factors are taken into account.

The results show that numeracy is strongly predictive of attrition, with the two most numerate groups more than $10 \%$ less likely to attrit amongst 5564 year olds, and more than $12 \%$ less likely to attrit among the 70-80 year olds. However, the inclusion of numeracy does little to diminish the size or significance of the education effect, suggesting that numeracy is not the principal explanation for the education gradient in attrition in ELSA. Attrition by numerical ability is, however, a serious cause for concern to which we return briefly in our conclusions.
The probit model estimated in Table 6 also includes additional variables relating to the administration of the ELSA interview for each respondent. These are certain procedural factors available in ELSA, which may be 'early warning signs' of subsequent attrition. For example, we know whether or not a respondent completed all the elements of the face to face interview or returned a partial interview, and we also know details relating to the return of their 'self-completion questionnaire' to the ELSA survey team. This questionnaire is given to all respondents at baseline, but many respondents (particularly those who are single) are left to fill this questionnaire in at their leisure, and return it to ELSA by post ${ }^{12}$. We have included a dummy variable for whether an individual failed to return this questionnaire completely, and another to indicate whether they returned it only after being sent a postal reminder by the ELSA team. As we might expect, failure to return the questionnaire is strongly predictive of subsequent attrition, being associated with a $17 \%$ (for $55-64$ year olds) or $21 \%$ (for $70-80$ year olds) increase in attrition. For many ELSA attritors, the decision to leave the survey may have occurred immediately after the baseline interview. Requiring a postal reminder, however, is not predictive of attrition (provided the individual did eventually return their questionnaire).

Another procedural parameter included in Table 6 relates to the success rate of the interviewer who conducted a respondent's first ELSA interview, the construction of which was described in the previous section. This variable ('Interviewer retention' in Table 6) has a large and highly significant association with attrition in both the 55-64 and 70-80 year old age groups - with individuals interviewed by someone who successfully retained many of their other subjects also more likely to remain in the survey themselves. In order to ensure that these interviewer retention rates are not simply capturing unobserved area effects, we experimented with adding regional identifiers, rural and urban dummy variables, and a combination of both ${ }^{13}$. Whilst the area effects were indeed significant predictors of attrition, in all cases the interviewer retention rate remained strongly statistically significant, with a large marginal effect. 
Table 6. The effect of numeracy and interview effectiveness - ELSA

(1)

Sample

VARIABLES

Numeracy indicator (base = group 1)

Numeracy group 2

Numeracy group 3

Numeracy group 4

Interview and self-completion outcomes:

Partial interview

Self completion not returned

Self completion with reminder

Interviewer retention rate

Highest qualification level:

Degree

Below degree

A level

O level

CSE

Foreign qualifications

F-test on region effects Observations
ELSA sample ELSA sample

aged 55-64 aged 70-80

Attrited between 2002 and 2006

$\begin{array}{cc}-0.043 & -0.076 \\ (1.65) & (2.88)^{* *} \\ -0.094 & -0.127 \\ (3.38)^{* *} & (4.18)^{* *} \\ -0.102 & -0.146 \\ (3.15)^{* *} & (3.44)^{* *}\end{array}$

$\begin{array}{cc}0.004 & -0.035 \\ (0.05) & (0.37) \\ 0.185 & 0.214 \\ (5.19)^{* *} & (5.17)^{* *} \\ 0.039 & 0.068 \\ (0.86) & (1.10) \\ -0.447 & -0.261 \\ (5.00)^{* *} & (2.44)^{*}\end{array}$

$-0.146$

$(5.55)^{* *}$

$-0.032$

$-0.126$

(0.73)

$(5.09) * *$

$-0.018$

(0.49)

$-0.091$

$(2.87)^{* *}$

$-0.068$

(1.21)

$-0.044$

$(2.04)^{*}$

$-0.006$

(0.19)

$-0.062$

(1.16)

(1.57)

$-0.022$

$(2.11)^{*}$

(0.65)

0.02

0.01

3431

2189

Notes. Other control variables are as in Table 5, namely: income and wealth quintiles, single year age dummies interacted with sex dummies, dummies for employment and health conditions at baseline, marital status, selfreported health and housing tenure. In addition, a full set of regional dummies was included.

Robust $z$ statistics in parentheses; * $p<0.05 ;{ }^{* *} p<0.01$ 
Our final line of investigation considers factors that are associated with return from attrition. As demonstrated in Figures 1 and 2, a subset of individuals who dropped out of these surveys between 2002 and 2004 subsequently return in 2006, with a return rate slightly higher in HRS than in ELSA. In order to search for attributes significantly correlated with return from attrition, we run a probit model using a sample of respondents who attrited between 2002 and 2004, with a dependent variable equal to one if an individual returned to the sample in 2006. Given the smaller sample size of attritors, we pool the entire sample aged 50 and above in each survey, and run a probit model of return from attrition on the following variables: income and wealth quintiles, education, a quadratic in age, dummy variables for employment and health conditions at baseline, marital status, self-reported health and housing tenure, all defined as in Table 5 . None of these variables was statistically significant, with the exception of college-education in the HRS (marginal effect $=-0.083, z=2.19)$, and being divorced in ELSA (marginal effect $=0.124, z=2.20$ ). For brevity, the full table of results is not presented (but is available from the authors, on request). These results suggest that it would be difficult for survey agencies to target the potential returnees from the pool of attritors based on their observable attributes in previous waves.

\section{Conclusions}

In this paper, we investigate the relative importance of sample attrition in two of the most important existing longitudinal studies of ageing - the English Longitudinal Survey of Ageing (ELSA) and the Health and Retirement Study (HRS). While attrition exists in both surveys, it is considerably higher in ELSA than in HRS. We explored several possible reasons for these differences, including some which seem unlikely to account for the gap (different rates of household mobility in the two countries, and different respondent burdens from the questionnaires), and several which may account for some (or all) of the gap, including survey maturity, differing sampling methods and survey administration, and differential financial incentives offered to respondents. Indeed, the large difference in financial incentives offered by the HRS and ELSA (the former offering a reward over 6 times the size of the latter) seems likely to play a significant role in explaining the difference in attrition - though the size of the effect cannot be tested without experimental or quasi-experimental variation which is not present in either survey.

The impact of sample attrition on the parameters of interest is not context free. In our application, we examine the impact of attrition on estimates of disease prevalence in the two countries. We find that sample attrition does not significantly affect conclusions regarding comparisons of disease prevalence, in part because in both univariate and multivariate contexts, attrition does not appear to be related to prior disease prevalence. Indeed, we find few attributes that are predictive of attrition in either survey. Attrition is negatively related to prior wave wealth in the HRS and negatively related to prior wave education and numerical ability in ELSA, suggesting that across these two dimensions, at least in these two older age groups, more care must be exercised in analysing the nature of the SES healthwealth gradient in HRS and the SES health-education gradient in ELSA. Housing tenure (specifically being a renter as opposed to an owner-occupier) predicts attrition in the HRS among individuals aged 55-64, suggesting that the high degree of mobility among renters in the U.S. may pose problems for survey administration. In neither survey do we find any attributes that appear to successfully identify who, among the prior wave attritors, the survey was able to bring back into the fold in subsequent waves.

\section{Acknowledgements}

This research was funded by grants from the National Institute of Aging R37-AG025529. Additional co-funding from the Economic and Social Research Council through the ESRC Centre for the Microeconomic Analysis of Public Policy at IFS (CPP) is gratefully acknowledged. Excellent programmer assistance was provided by Iva MacLennan and David Rumpel. 


\section{References}

Attanasio O and Hoynes H. (2000) Differential mortality and wealth accumulation. Journal of Human Resources, 35, 1-29.

Banks J, Marmot M, Oldfield Z and Smith JP. (2006) Disease and disadvantage in the United States and in England. Journal of the American Medical Association (JAMA), 295, 2037-2045.

Banks J and Oldfield Z. (2007) Understanding pensions: cognitive function, numerical ability and retirement saving. Fiscal Studies, 28, 143-170.

Banks J, Muriel A and Smith JP. (2010) Disease prevalence, disease incidence, and mortality in the United States and in England. Demography (forthcoming).

Banks J, Oldfield Z and Smith JP. (2009) Housing mobility at older ages in England and the United States. Paper presented at the 2009 American Economic Association meetings.

Becketti S, Gould W, Lillard L and Welch F. (1988) The Panel Study of Income Dynamics after fourteen years: an evaluation. Journal of Labor Economics, 6, 472-92.

Fitzgerald J, Gottschalk P and Moffitt R. (1998) An analysis of sample attrition in panel data: the Michigan Panel Study of Income Dynamics. Journal of Human Resources, 33, 251-299.

Groves R and Couper M. (1998) Nonresponse in household interview surveys. New York, Wiley.

Hausman J and Wise D. (1979) Attrition bias in experimental and panel data: the Gary Income Maintenance Experiment. Econometrica, 47,455-74.

Hayward M, Crimmins E, Miles T and Yang Y. (2000) The significance of socioeconomic status in explaining the race gap in chronic health conditions. American Sociological Review, 65, 910-930.

Hill DH and Willis RJ. (2001) Reducing panel attrition: a search for effective policy instruments. Journal of Human Resources, 36, 416-438.

Juster FT and Smith JP. (1997) Improving the quality of economic data: lessons from the HRS and AHEAD. Journal of the American Statistical Association, 92, 1268-78.

Juster FT and Suzman R. (1995) An overview of the Health and Retirement Study. Journal of Human Resources, 30, S7-S56.

Laurie $\mathrm{H}$ and Lynn P. (2009) The use of respondent incentives on longitudinal surveys. In P Lynn ed. Methodology of Longitudinal Surveys. Wiley, West Sussex.

Lillard L and Panis CW. (1998) Panel attrition from the Panel Study of Income Dynamics: household income, marital status and mortality. Journal of Human Resources, 33, 437-457.

Little R and Rubin D. (1987) Statistical analysis with missing data. Wiley, New York.

Smith JP. (2007) The impact of socioeconomic status on health over the life-course. Journal of Human Resources, $42,739-764$.

Marmot M, Banks J, Blundell R, Lessof C and Nazroo J. (2003) Introduction to health, wealth and lifestyles of the older population in England; the 2002 English Longitudinal Study of Ageing. Institute for Fiscal Studies, London.

Rodgers, WL. (2002) Size of incentive effects in a longitudinal study. Presented at the 57th Annual Meeting of the American Association for Public Opinion Research, St. Pete Beach, Florida.

Sudman S and Bradburn N. (1974) Response efforts in surveys. (1974) Aldine, Chicago.

Thomas D, Frankenberg E and Smith JP. (2001) Lost but not forgotten: attrition and follow-up in the Indonesia Family Life Survey. Journal of Human Resources 36, 556-592.

Weir D and Smith JP. (2007) Do panel surveys really make people sick? U.S. arthritis trends in the Health and Retirement Study. Social Science and Medicine 65, 2263-2267.

Zabel J. (1998) An Analysis of Attrition in the PSID and the Survey of Income and Program Participation. Journal of Human Resources, 33, 479-506. 


\section{Appendix}

Derivation of numeracy classification variables.

\section{Box 1a. Numeracy items in ELSA questionnaire}

q1) If you buy a drink for 85 pence and pay with a one pound coin, how much change should you get?

q2) In a sale, a shop is selling all items at half price. Before the sale a sofa costs $£ 300$. How much will it cost in the sale?

q3) If the chance of getting a disease is 10 per cent, how many people out of 1,000 would be expect to get the disease?

q4) A second hand car dealer is selling a car for $£ 6,000$. This is two-thirds of what it cost new. How much did the car cost new?

q5) If 5 people all have the winning numbers in the lottery and the prize is $£ 2$ million, how much will each of them get?

q6) Let's say you have $£ 200$ in a savings account. The account earns ten per cent interest per year. How much will you have in the account at the end of two years?

\section{Box 1b. Construction of broad cognitive function categories}

Classification Response to questions

Proportion of sample

Group I Either: q2, q3, q4 all incorrect

$16.24 \%$

Or: $\quad$ q2 correct; q3, q4, q5 all incorrect

$46.46 \%$

Group II At least one of q2, q3, q4, q5 incorrect; q6 incorrect

$26.08 \%$

Group III

Either: q2, q3, q4, q5 correct; q6 incorrect

Or: At least one of q2, q3, q4 correct; q5 q6 correct

Group IV q2, q3, q4, q5, q6 correct

$11.22 \%$ 


\section{Endnotes}

${ }^{1}$ In each country, the linked data (the National Death Index in the US and the National Health Service Central Register Database in England) is the data which, at the population level, is used to compute official life tables.

${ }^{2}$ http://www.share-project.org

${ }^{3}$ Heart problems are not included directly in Table 1, as we do not have a perfectly comparable measure of heart complaints between the two surveys. ELSA asks about a series of specific conditions: angina, congestive heart failure, heart murmur and heart attack. The HRS, in contrast, asks a generic question about heart problems in general.

${ }^{4}$ Even this is not a full summary since new spouses can join the survey at any wave.

${ }^{5}$ We use the word 'imperfect' since occasionally ELSA respondents who prove difficult to contact (or reluctant to respond) are handed to some of the most experienced members of the interview team, so that the 'best' interviewers are often allocated the hardest cases. Since cases are therefore not completely randomly assigned, the attrition rate of an interviewer is therefore not a perfect guide to interviewer quality. This is less of a problem at baseline.

${ }^{6} 75.8 \%$ is the mean retention rate without weighting to take into account the number of interviews conducted by each interviewer. When we weight by number of interviews, the mean retention rate matches ELSA's overall retention rate of $77.6 \%$.

${ }^{7}$ Wealth quintiles are defined within age groups, and are based on the net total non-pension wealth of the respondent and their spouse (if present).

${ }^{8}$ These variables differ between the models for the U.S. and England, reflecting the different education systems in the two countries.

${ }^{9}$ Nor is this lack of significant baseline health effects due to our choice of ten year age bands - when we re-estimate the model pooling all respondents aged 50 and over (results available upon request), we again find no significant effects of baseline health conditions, with the exception of arthritis.

${ }^{10}$ There were no HRS respondents in this sample with missing self-reported health.

${ }^{11}$ Results available from the authors on request.

${ }^{12}$ For couples who are interviewed simultaneously, however, one member of the couple is asked to fill in the questionnaire while the other undergoes the face to face interview, so that no posting is required.

${ }^{13}$ We thank an anonymous referee for this suggestion. 